DOI: https://doi.org/10.33330/jurteksi.v5i1.324

Available online at http://jurnal.stmikroyal.ac.id/index.php/jurteksi

\title{
IMPLEMENTASI DATA MINING DALAM ANALISA POLA PEMINJAMAN BUKU DI PERPUSTAKAAN MENGGUNAKAN METODE ASSOCIATION RULE
}

\author{
Edi Kurniawan \\ Sistem Informasi, STMIK Royal Kisaran \\ e-mail: edikurniawan.royal@gmail.com
}

\begin{abstract}
The library is one of the most important means to add insight and knowledge to everyone. In general, borrowing transaction data books that exist in a library are only left to accumulate by the library in the database without any utilization or further processing of the data that has long been stored. By utilizing the Data Mining technique using association rules with FP-Growth, these data will be very useful. Because from the data lending books to the library, new information can be gleaned about what books are often borrowed and know the pattern of relationships between books that have been borrowed together so that later it can be used to compile books in accordance with the existing borrowing patterns so that they can facilitate library visitors in the process of finding books.
\end{abstract}

Keywords: Data Mining, Association Rule, FP-Growth, Library

\begin{abstract}
Abstrak: Perpustakaan merupakan salah satu sarana yang sangat penting untuk menambah wawasan dan keilmuan setiap orang. Pada umumnya data transaksi peminjaman buku yang ada pada sebuah perpustakaan hanya dibiarkan saja menumpuk oleh pihak perpustakaan di dalam database tanpa ada pemanfaatan atau pengolahan lebih lanjut dari data-data yang telah lama tersimpan tersebut. Dengan melakukan pemanfaatan menggunakan Teknik Data Mining metode association rules dengan FP-Growth, datadata tersebut akan jadi sangat bermanfaat. Karena dari data peminjaman buku pada perpustakaan tersebut dapat diggali informasi baru tentang buku-buku apa yang sering dipinjam dan mengetahui pola hubungan antara buku yang telah dipinjam secara bersama-sama sehingga nantinya dapat dimanfaatkan untuk melakukan penyusunan buku sesuai dengan pola peminjaman buku yang ada sehingga dapat mempermudah para pengunjung perpustakaan dalam proses pencarian buku.
\end{abstract}

Kata Kunci : Data Mining, Asociation Rule, FP-Growth, Perpustakaan

\section{PENDAHULUAN}

Perpustakaan merupakan salah satu sarana yang sangat penting untuk menambah wawasan dan keilmuan setiap orang. Data transaksi peminjaman buku merupakan data yang sangat penting bagi sebuah perpustakaan sehingga setiap ada transaksi peminjaman di perpustakaan maka data transaksi tersebut akan disimpan ke dalam gudang data. Salah satu upaya untuk menggali informasi dan pengetahuan 
DOI: https://doi.org/10.33330/jurteksi.v5i1.324

Available online at http://jurnal.stmikroyal.ac.id/index.php/jurteksi

yang berharga pada database yang sangat besar disebut Data Mining. Pada umumnya data transaksi peminjaman buku yang ada pada sebuah perpustakaan hanya dibiarkan saja menumpuk oleh pihak perpustakaan di dalam database tanpa ada pemanfaatan atau pengolahan lebih lanjut dari datadata yang telah lama tersimpan tersebut. Padahal apabila diolah menggunakan teknik Data Mining, data-data tersebut akan sangat bermanfaat.

Dengan memanfaatkan metode FP-Growth dengan aturan asosiasi (association rules) sehingga dapat diggali informasi tentang buku-buku apa yang sering dipinjam dan mengetahui pola hubungan antara buku yang telah dipinjam secara bersama-sama sehingga nantinya dapat dimanfaatkan untuk melakukan penyusunan buku sesuai dengan pola peminjaman buku yang ada sehingga dapat mempermudah para pengunjung perpustakaan dalam proses pencarian buku. Di dalam jurnal ini akan dibahas bagaimana Teknik Data mining FP-Growth dengan Association Rules dapat digunakan dalam menghasilkan informasi yang berharga bagi pihak perpustakaan dengan memanfaatkan hasil analisa pola dari data transaksi peminjaman buku pada perpustakaan.

Data Mining Menurut Priyanka dan Kumar (2014), Data Mining adalah proses ekstraksi informasi berharga dan tidak diketahui dari database yang besar[1]. Data Mining adalah proses menganalisis data yang besar dari perspektif yang berbeda dan meringkas menjadi informasi yang berguna. Informasi tersebut dapat diubah menjadi pengetahuan tentang pola-pola historis.

Association Rules Menurut Zhang, yang dikutip dari Rama Novta Miraldi, et al (2014)[2]. Association rule merupakan salah satu metode yang bertujuan mencari pola yang sering muncul di antara banyak transaksi, dimana setiap transaksi terdiri dari beberapa item sehingga metode ini akan mendukung sistem rekomendasi melalui penemuan pola antar item dalam transaksi-transaksi yang terjadi.

FP-Growth Wang, et al. (2010), mengatakan bahwa dalam algoritma Association Rule konvensional, pemindaian database membutuhkan waktu yang sangat besar terutama ketika seseorang menggunakan algoritma Apriori, yang sering mempengaruhi efisiensi dalam Data Mining. Untuk mengatasi hal tersebut dapat digunakan metode Data Mining yang disebut Frequent Pattern-Growth (FP-Growth), yang tidak perlu untuk menghasilkan generate candidate item sets dan dianggap lebih efisien (Wiwit Agus Triyanto, et al. 2014)[3].

Menurut Jiawei dan Kamber, yang dikutip oleh Erwin (2009) mengatakan, Metode FP-Growth dapat dibagi menjadi 3 tahapan utama yaitu sebagai berikut[4]:

1) Tahap pembangkitan conditional pattern base

2) Tahap pembangkitan conditional FP-Tree, dan

3) Tahap pencarian frequent itemset. Untuk Proses diatas dapat di Didalam melakukan proses tahapan tersebut dapat diperoleh melalui proses berikut: 
DOI: https://doi.org/10.33330/jurteksi.v5i1.324

Available online at http://jurnal.stmikroyal.ac.id/index.php/jurteksi

\section{Support}

Support dapat dirumuskan sebagai berikut :(1)

Support $=P(A \cap B)=\frac{\text { Jumlah Transaksi Yang Memuat } A \text { dan } B}{\text { Total Jumlah Transaksi }}$

2. Confidence

Confidence dihasilkan dari seberapa kuat hubungan produk yang sudah dibeli. Confidence dapat dirumuskan sebagai berikut

$$
\text { Confidence }=P(B \mid A)=\frac{\text { Support }(A \cap B)}{P(A)}
$$

\section{Lift Ratio}

Lift Ratio merupakan nilai yang menunjukan kevalidan proses transaksi dan memberikan informasi apakah benar produk A dibeli bersamaan dengan produk B. Lift Ratio dapat dirumuskan sebagai berikut :

Lift Ratio $=\frac{\text { Support }(A \cap B)}{\text { Support }(A) * \text { Support }(B)}$

Ruang lingkup masalah pada penelitian ini adalah:

1. Data yang digunakan adalah data transaksi peminjaman buku di perpustakaan umum Kabupaten Asahan dengan meggunakan data akhir tahun 2013 sampai 2016 awal.

2. Analisa transaksi peminjaman buku hanya dilakukan dengan sample yang sudah tersedia.

3. Metode yang digunakan untuk analisa hanya menggunakan metode FP-Growth dengan aturan asosiasi.

4. Pengujian dilakukan menggunakan alat bantu (tools) RapidMiner 5.3.

Tujuan penelitian ini adalah:

1. Untuk mengenali atau mengetahui pola peminjaman item buku dengan metode FPGrowth.
2. Untuk mengetahui keterhubungan / keterkaitan antara suatu item buku dengan buku lainnya.

3. Menganalisa data transaksi peminjaman buku dengan aturan asosiasi menggunakan metode FP-Growth .

4. Menerapkan metode FP-Growth terhadap data terkait menggunakan suatu tools yang telah ada.

5. Menguji data yang telah tersedia dengan metode FP-Growth menggunakan alat bantu (tools) atau sistem yang sudah ada.

\section{METODE}

Kerangka kerja penelitian ini dibuat sebagai pedoman dalam melaksanakan penelitian dan disusun ke dalam bentuk sebuah kerangka kerja (framework), dimana pada kerangka kerja yang dibuat dapat dilihat kegiatan-kegiatan dalam melakukan penelitian ini

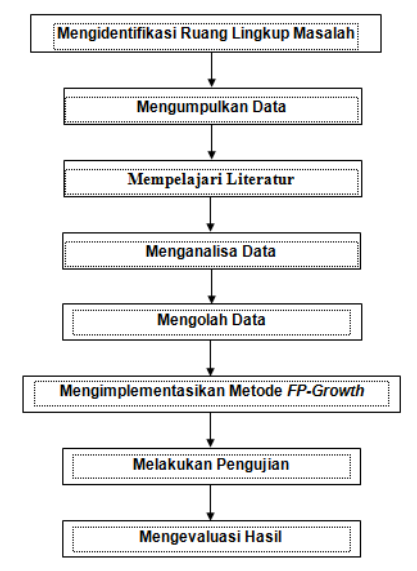

Gambar 1. Kerangka Kerja Penelitian.

\section{PEMBAHASAN}


DOI: https://doi.org/10.33330/jurteksi.v5i1.324

Available online at http://jurnal.stmikroyal.ac.id/index.php/jurteksi

Setelah dilakukan pengolahan data awal, selanjutnya data yang dihasilkan akan dilakukan analisa data dengan mengambil sebagian data peminjaman buku di perpustakaan umum Kabupaten Asahan yang akan digunakan sebagai data training. Pada data training dipilih beberapa transaksi pemin-jaman dari beberapa jenis buku.

Support count yang yang diberikan adalah 20\%, maka item yang berpengaruh dan akan dimasukkan ke dalam FP-Tree adalah item \{Cerita Rakyat Asahan, Guru Profesional, Cerita Rakyat Asahan II, Cerita Rakyat Asahan III, Menjadi Guru Teladan, 366 Cerita Rakyat Indonesia\}, selebihnya untuk item yang frekuensi kemunculannya di bawah 20\% maka dapat dibuang karena tidak berpengaruh signifikan.

Agar mempermudah dalam menggambarkan struktur FP-Tree maka dapat diberikan inisial terhadap masing-masing item agar label pada setiap cabang yang terdiri dari itemitem tidak terlalu panjang.

\begin{tabular}{lc}
\hline \multicolumn{1}{c}{ Item } & inisial \\
\hline Cerita Rakyat Asahan & $\mathrm{a}$ \\
\hline Guru Profesional & $\mathrm{b}$ \\
\hline Cerita Rakyat Asahan II & $\mathrm{c}$ \\
\hline Cerita Rakyat Asahan III & $\mathrm{d}$ \\
\hline Menjadi Guru Teladan & $\mathrm{e}$ \\
\hline 366 Cerita Rakyat & $\mathrm{f}$ \\
Indonesia & \\
\hline
\end{tabular}

Tabel 1. Inisial Item.

Proses dalam pembangkitan FP-Tree dimulai dengan pembacaan TID 1 atau transaksi yang pertama, kemudian dilanjutkan dengan TID 2 (transaksi kedua), dan diteruskan dengan transaksi berikutnya sampai transaksi terakhir. Adapun proses dalam pembangkitan FP-Tree dari

Tabel 2. Data Training

\begin{tabular}{|c|c|}
\hline TID & Item Yang Dipinjam \\
\hline 296_2013 & $\begin{array}{l}\text { \{Kebijakan Pendidikan, Guru Profesional, Menjadi Guru } \\
\text { Teladan }\}\end{array}$ \\
\hline 352_2013 & $\begin{array}{l}\text { \{Cerita Rakyat Asahan, Cerita Rakyat Asahan II, Cerita Rakyat } \\
\text { Asahan III }\}\end{array}$ \\
\hline 389_2013 & $\begin{array}{l}\text { \{Guru Profesional, Cerita Rakyat Asahan, Cerita Rakyat Asahan } \\
\text { II }\end{array}$ \\
\hline 428_2013 & $\begin{array}{l}\text { \{Buku Pintar Kultum, } 366 \text { Cerita Rakyat Indonesia, Cerita } \\
\text { Rakyat Asahan }\}\end{array}$ \\
\hline 462_2013 & $\begin{array}{l}\text { \{Guru Profesional, Complete English Grammer, Cerita Rakyat } \\
\text { Asahan III }\}\end{array}$ \\
\hline 200_2014 & \{Air Mata Nabi, 366 Cerita Rakyat Indonesia\} \\
\hline 216_2014 & $\begin{array}{l}\text { \{Cerita Rakyat Asahan, Cerita Rakyat Asahan II, Cerita Rakyat } \\
\text { Asahan III }\}\end{array}$ \\
\hline $118 \_2015$ & $\begin{array}{l}\text { \{Cerita Rakyat Asahan, Cerita Rakyat Asahan II, Cerita Rakyat } \\
\text { Asahan III }\}\end{array}$ \\
\hline 450_2015 & \{Media Pendidikan, Guru Profesional, Menjadi Guru Teladan $\}$ \\
\hline 479_2015 & $\{$ Belajar dan Pembelajaran, Guru Profesional $\}$ \\
\hline
\end{tabular}


DOI: https://doi.org/10.33330/jurteksi.v5i1.324

Available online at http://jurnal.stmikroyal.ac.id/index.php/jurteksi

Data training yang digunakan dapat dilihat pada penjelasan berikut

\section{Pembacaan TID 1}

Pada transaksi pertama atau TID 1 item yang pinjam adalah $\{\mathrm{b}, \mathrm{e}\}$ yang kemudian akan membuat simpul $b$ dan e, sehingga terbentuk lintasan Null $\rightarrow \mathrm{b} \rightarrow \mathrm{e}$ dengan support count dari setiap simpul bernilai 1. Adapun ilustrasi pembentukan FP-Tree dari TID 1 yang berisikan item $\{b, e\}$ dapat dilihat pada gambar 4.2.

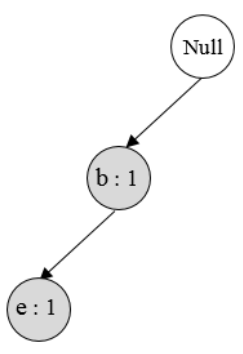

Gambar 2. Pembentukan FP-Tree TID 1

2. Pembacaan TID 2

Selanjutnya pembentukan FPTree dilakukan dengan membaca TID 2 atau transaksi yang selanjutnya. Pada TID 2 item yang dipinjam adalah $\{\mathrm{a}, \mathrm{c}, \mathrm{d}\}$ sehingga terbentuk lintasan kedua yaitu Null $\rightarrow \mathrm{a} \rightarrow \mathrm{c} \rightarrow \mathrm{d}$ dengan support count masingmasing item bernilai 1 .

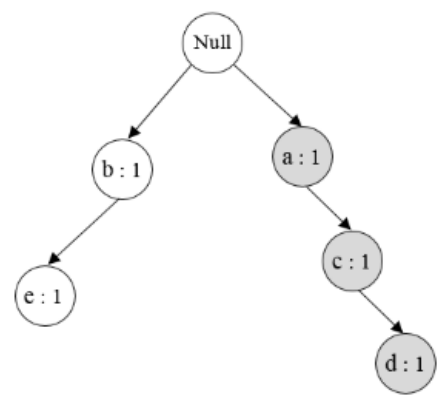

Gambar 3. Pembentukan FP-Tree TID 2

3. Pembacaan TID 10

Pada TID 10 item yang dipinjam adalah $\{b\}$, sehingga terbentuk lintasan kesepuluh yaitu Null $\rightarrow$ b. Karena transaksi ini juga memiliki prefix (awalan) yang sama dengan transaksi yang ada sebelumnya, maka lintasan tersebut dapat ditimpakan sambil menambah-kan support count dari lintasan tersebut sehingga support count b menjadi bernilai

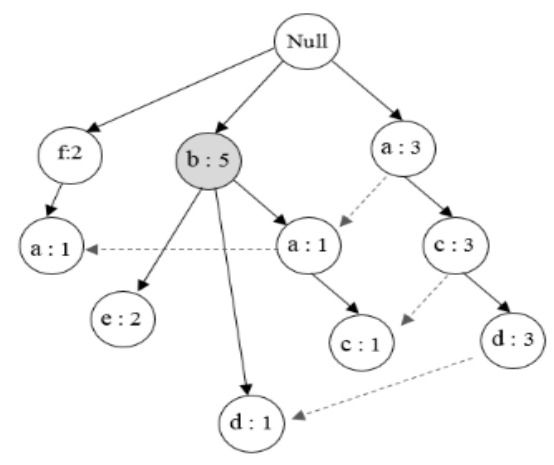

Gambar 4. Pembentukan FP-Tree TID 10

Setelah tahap pembentukan $F P$ Tree, maka langkah selanjutnya adalah tahap pembangkitan conditional pattern base. didalam tahap ini dapat dilakukan dengan melihat kembali FP-Tree yang sudah dibuat sebelumnya.

\section{Tabel 3. Hasil Condition Pattern Base}

\begin{tabular}{cl}
\hline Suffix & Conditional Pattern Base \\
\hline $\mathrm{e}$ & $\{\{\mathrm{b}: 2\}\}$ \\
\hline $\mathrm{d}$ & $\{\{\mathrm{a}, \mathrm{c}: 3\},\{\mathrm{b}: 1\}\}$ \\
\hline $\mathrm{c}$ & $\{\{\mathrm{b}, \mathrm{a}: 1\},\{\mathrm{a}: 3\}\}$ \\
\hline $\mathrm{a}$ & $\{\{\mathrm{f}: 1\},\{\mathrm{b}: 1\}\}$ \\
\hline
\end{tabular}


DOI: https://doi.org/10.33330/jurteksi.v5i1.324

Available online at http://jurnal.stmikroyal.ac.id/index.php/jurteksi

Setelah tahap pembangkitan conditional pattern base dilakukan, maka tahap selanjutnya adalah pembangkitan conditional FP-Tree. Conditional FP-Tree mirip dengan FP-Tree biasa yang terdapat sebelumnya, namun conditional FPTree dimaksudkan untuk mencari frequent itemset yang berakhiran item tertentu atau mengandung suffix (akhiran) yang sama. Apabila nilai dari support count pada simpul item memenuhi minimum support maka item tersebut merupakan frequent.

Tabel 4. Hasil Condition FP-Tree Suffix Conditional FP-Tree

\begin{tabular}{ll}
\hline $\mathrm{e}$ & $\{\{\mathrm{b}: 2\}\}$ \\
\hline $\mathrm{d}$ & $\{\{\mathrm{a}, \mathrm{c}: 3\}\}$ \\
\hline $\mathrm{c}$ & $\{\{\mathrm{a}: 4\}\}$ \\
\hline
\end{tabular}

Tabel 5. Hasil Frequent Itemset

\begin{tabular}{cl}
\hline Suffix & Conditional FP-Tree \\
\hline e & $\{\mathrm{e}\},\{\mathrm{b}, \mathrm{e}\}: 2$ \\
\hline $\mathrm{d}$ & $\{\mathrm{d}\},\{\mathrm{a}, \mathrm{d}\}: 3,\{\mathrm{c}, \mathrm{d}\}: 3$ \\
& $\{\mathrm{a}, \mathrm{c}, \mathrm{d}\}: 3$ \\
\hline $\mathrm{c}$ & $\{\mathrm{c}\},\{\mathrm{a}, \mathrm{c}\}: 4$ \\
\hline
\end{tabular}

II), maka akan meminjam item a (Cerita Rakyat Asahan) juga, jika meminjam item a (Cerita Rakyat Asahan), maka akan meminjam item c (Cerita Rakyat Asahan II) juga, dan jika jika meminjam item c (Cerita Rakyat Asahan II), maka akan meminjam item a (Cerita Rakyat Asahan) juga.

Adapun hasil lengkap pola-pola atau rules yang dihasilkan dapat dilihat pada tabel. 6

Proses analisa yang dilakukan secara manual hanya menggunakan data training atau data sample dengan jumlah data 10 transaksi.

Selanjutnya melakukan pengujian terhadap data transaksi peminjaman buku di Perpustakaan Umum Kabupaten Asahan, dengan menggunakan data dari tahun 2013 novepember sampai 2015 desember dengan jumlah data transaksi 505 transaksi dan jumlah atribut sebanyak 255 atribut. Dengan nilai minimun support $=0.004$ dan nilai minimum confidence $=0.75$.

Tabel 6. Hasil Frequent Itemset

\begin{tabular}{|c|c|c|c|}
\hline Jika Meminjam & $\begin{array}{l}\text { Maka Akan } \\
\text { Meminjam }\end{array}$ & Support & $\begin{array}{c}\text { Confide } \\
\text { nce }\end{array}$ \\
\hline $\begin{array}{l}\text { (d) Cerita Rakyat Asahan III, (c) } \\
\text { Cerita Rakyat Asahan II }\end{array}$ & $\begin{array}{l}\text { (a) Cerita } \\
\text { Rakyat Asahan }\end{array}$ & $30 \%$ & $100 \%$ \\
\hline $\begin{array}{l}\text { (a) Cerita Rakyat Asahan, (d) Cerita } \\
\text { Rakyat Asahan III }\end{array}$ & $\begin{array}{l}\text { (c) Cerita } \\
\text { Rakyat Asahan } \\
\text { II }\end{array}$ & $30 \%$ & $100 \%$ \\
\hline (a) Cerita Rakyat Asahan & $\begin{array}{l}\text { (c) Cerita } \\
\text { Rakyat Asahan } \\
\text { II }\end{array}$ & $40 \%$ & $80 \%$ \\
\hline (c) Cerita Rakyat Asahan II & $\begin{array}{l}\text { (a) Cerita } \\
\text { Rakyat Asahan }\end{array}$ & $40 \%$ & $100 \%$ \\
\hline
\end{tabular}


JURTEKSI (Jurnal Teknologi dan Sistem Informasi)

Vol. V No. 1, Des 2018, hlm. 89 - 96

DOI: https://doi.org/10.33330/jurteksi.v5i1.324

Available online at http://jurnal.stmikroyal.ac.id/index.php/jurteksi

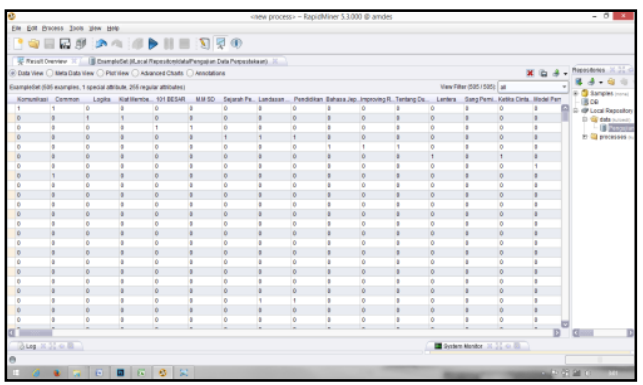

Gambar 5. Data Transaksi Peminjaman Buku Perpustakaan Umum Kabupaten Asahan

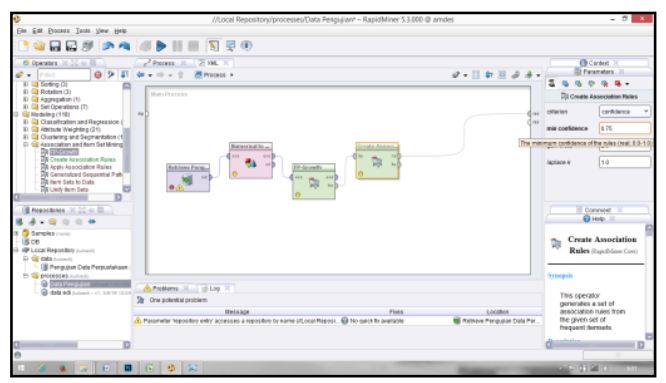

Gambar 6. Proses Unutk

Mendapatkan Asociation Rule.

Adapun hasil yang didapat setelah dilakukan proses pengolahan aplikasi RapidMiner, terdapat 9 rules.

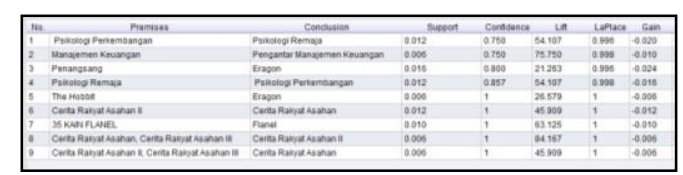

Gambar . Hasil Asociation Rule yang diperoleh.

Setelah dilakukan pengujian terhadap data transaksi peminjaman buku yang ada menggunakan aplikasi RapidMiner versi 5.3, dengan jumlah data sebanyak 505 transaksi yang terdiri dari 255 atribut, telah dihasilkan pengetahuan baru yang berharga berupa pola-pola hubungan kombinasi item sebanyak 9 rules atau 9 kombinasi item yang dapat digunakan sebagai informasi untuk tata letak buku di perpustakaan
ISSN 2407-1811 (Print)

ISSN 2550-0201 (Online) umum Kabupaten Asahan sesuai dengan asociation rule yang ada.

\section{SIMPULAN}

Berdasarkan hasil analisa dan pembahasan Data Mining menggunakan metode $\mathrm{FP}$-Growth yang dilakukan maka dapat ditarik kesimpulan sebagai berikut :

1. Dari hasil analisa yang telah dilakukan didapat pengetahuan baru yang dapat dimanfaatkan oleh pihak Perpustakaan Umum Kabupaten Asahan, yaitu pengetahuan mengenai pola-pola hubungan kombinasi items apa saja yang dipinjam secara bersamaan, di mana dari pengujian yang dilakukan dengan jumlah transaksi sebanyak 505 dengan nilai support $=0,004$ dan nilai confidence $=0,75$ telah menghasilkan 9 rules yang dapat dijadikan sebagai pengetahuan baru yang berharga.

2. Metode FP-Growth dengan aturan asosiasi mampu mengenali pola peminjaman buku (item) atau mengenali pola sifat peminjaman buku oleh peminjam dengan cepat. Sebagai contoh dari pengujian yang telah dilakukan diketahui bahwa apabila konsumen membeli Jika meminjam buku \{Psikologi Perkembangan $\}$ maka akan meminjam buku \{Psikologi Remaja\}.

3. Implementasi Data Mining untuk analisa pola transaksi peminjaman buku dengan mudah dan cepat menggunakan aplikasi RapidMiner versi 5.3.

4. Hasil asosiasi yang didapat bisa digunakan untuk meningkatkan 
DOI: https://doi.org/10.33330/jurteksi.v5i1.324

Available online at http://jurnal.stmikroyal.ac.id/index.php/jurteksi

pelayanan di Perpustakaan Umum Kabupaten Asahan, seperti penentuan tata letak buku pada suatu rak dan pembuatan sistem rekomendasi buku.

\section{DAFTAR PUSTAKA}

[1] Priyanka and Er. Vinod, K. S. 2014. Apriori Algorithm For Mining Frequent Itemsets-A Review. International Journal of Computer Application and Engineering Technology. 3 (3): 232-236.

[2] Donny, M. V. dan Imam, M. 2013. "Aplikasi Association Rule Mining Untuk Menemukan Pola Pada Data Nilai Mahasiswa Matematika ITS. Jurnal Sains dan Seni POMITS. 1 (1): 1-6.

[3] Ali Ikhwan, Dicky N, Sriani. 2014. Penerapan Data Mining dengan Algoritma Fp-Growth untuk Mendukung Strategi Promosi Pendidikan. Jurnal Ilmiah Saintikom. 211-226.

[4] Erwin. 2009. Analisis Market Basket Dengan Algoritma Apriori dan FP-Growth. Jurnal Generic. 4 (2): 26-30.

[5] Syafnur, Afdhal. "Analisis Dengan Metode Klasifikasi Menggunakan Decission Tree Untuk Memprediksi Penentuan Resiko kredit Bank." JURTEKSI 4.1 (2017): 101-106.

[6] Kennedi, T., Hoga, S. dan Bobby, R. 2013. Implementasi Data Mining Algoritma Apriori Pada Sistem Persediaan AlatAlat Kesehatan. Informasi dan Teknologi Ilmiah (INTI). 1 (1):
93-106.

[7] Phani, P. J. and Murlidher, M. 2013. A Study on Market Basket Analysis Using a Data Mining Algorittm. International Jour-nal of Emerging Technology and Advanced Engineering. 3 (6): 361-363. 